\title{
Evidence that stimulus generalization does not determine taste-mediated odor potentiation
}

\author{
MARK T. BOWMAN, W. ROBERT BATSELL, JR., \& MICHAEL R. BEST \\ Southern Methodist University, Dallas, Texas
}

\begin{abstract}
A between-group design was utilized in two experiments to determine the contribution of stimulus generalization to taste-mediated odor potentiation. In Experiment 1, almond odor overshadowed a denatonium saccharide aversion compared with a taste-alone control, whereas denatonium potentiated the almond odor aversion relative to an odor-alone group. Generalization between these stimuli was investigated in Experiment 2. The results of Experiment 2 showed that neither almond nor denatonium demonstrated significant generalization to the other. These results indicate that stimulus generalization is not the central mechanism of taste-mediated odor potentiation.
\end{abstract}

When an odor is mixed with a taste and consumption of this compound is followed by toxicosis, aversion to the odor is generally potentiated whereas aversion to the taste is typically overshadowed (for a review, see LoLordo \& Droungas, 1989). Although stimulus generalization is not an obvious factor in the production of taste-mediated potentiation of stimuli not mixed with the edible (e.g., environmental stimuli: Best, Brown, \& Sowell, 1984; distal odors: Bouton, Jones, McPhillips, \& Swartzentruber, 1986; auditory stimuli: Ellins, Cramer, \& Whitmore, 1985), Durlach and Rescorla (1980) noted the potential importance of generalization between a taste and an odor when they are conditioned in a mixture. The present experiments were designed to investigate the contribution of stimulus generalization to taste-mediated odor potentiation.

Four experiments were conducted. In Experiment 1a, aversion to almond was measured after conditioning with a mixture of the bitter denatonium saccharide and almond. In Experiment $1 \mathrm{~b}$, aversion to the bitter taste (denatonium saccharide) was evaluated when it was conditioned in compound with an odor (almond). Finally, in Experiment 2a, generalized aversion to almond was evaluated following conditioning with denatonium saccharide, and in Experiment $2 \mathrm{~b}$, denatonium was tested following conditioning with almond.

\section{EXPERIMENT 1}

\section{Method}

Subjects (Experiment 1a). The subjects were 24 experimentally naive, adult male Holtzman rats born and reared in the SMU vivarium. Illumination was set on a 12:12-h light:dark cycle. The animals were individually housed in Wahmann cages and had free access to Purina Rat Chow. Also, for 3 weeks prior to experimental manipulations, the ani-

This research was supported by NSF Grant BNS-8809508. Portions of this report were used for partial fulfillment of the Master of Science degree by the first author. The authors thank Howard Hurd and Chris Jones for their help on this project. Reprints are available from M. R. Best, Department of Psychology, Southern Methodist University, Dallas, TX 75275 . mals were on a 23.6-h water-deprivation schedule, receiving 20-min access to $40 \mathrm{ml}$ of water at approximately $1200 \mathrm{~h}$ each day. All fluids were presented in calibrated $50-\mathrm{ml}$ polypropylene drinking tubes. All manipulations occurred in the familiar home cage.

Apparatus (Experiment 1a). The odor stimulus was a 1.0\% almond odor solution (1 cc of Adam's Almond Odor Extract mixed with $99 \mathrm{cc}$ of tap water), and the taste stimulus was a $1 / 10,000$ denatonium solution $(0.1 \mathrm{~g}$ denatonium saccharide mixed with 1 liter tap water). These two solutions were combined to make the denatonium-almond compound solution. Toxicosis conditioning was achieved by means of an i.p. injection of $0.15 \mathrm{M}$ lithium chloride ( $\mathrm{LiCl} ; 12 \mathrm{mg} / \mathrm{kg}$ of body weight).

Procedure (Experiment 1a). The animals were matched to three groups $(n=8)$ according to daily water intake during the water-deprivation schedule. The groups differed in terms of their conditioning fluid: Group AL consumed almond solution, Group DEN consumed denatonium solution, and Group DEN + AL drank the denatonium-almond compound solution. For conditioning, $10 \mathrm{ml}$ of each fluid was presented for $10 \mathrm{~min}$. Fifteen minutes after this 10 -min exposure, all animals were injected with $\mathrm{LiCl}$. Five hours after conditioning, all groups were given their daily water allowance. Testing occurred $72 \mathrm{~h}$ after conditioning, with all animals receiving access to $30 \mathrm{ml}$ of the almond solution for $20 \mathrm{~min}$.

Subjects, Apparatus, and Procedure (Experiment 1b). Twenty-four naive, adult male Holtzman rats served as subjects in Experiment $1 \mathrm{lb}$. All procedures and groups $(n=8)$ were the same as those described in Experiment la except that the groups (AL, DEN, and DEN $+A L$ ) were tested with denatonium instead of the almond solution.

\section{Results and Discussion}

Experiment 1a. All three groups consumed relatively equal amounts on the day preceding conditioning and during conditioning. Mean intake on the day preceding conditioning ranged from 19.6 to $20.7 \mathrm{ml}$ and during conditioning from 6.1 to $7.8 \mathrm{ml}$.

Figure 1 presents the mean almond intake for the three groups in Experiment 1a. A one-way analysis of variance (ANOVA) demonstrated a significant difference between the three groups $[F(2,23)=21.2, p<.01]$. Betweengroup comparisons (Newman-Keuls) revealed all groups to be significantly different from each other, that is, the $\mathrm{DEN}+\mathrm{AL}$ group drank significantly less almond than both the DEN and AL groups, and the AL group drank less almond than the DEN group.

Experiment 1b. The three groups of Experiment $1 b$ drank approximately the same amounts on the day preceding conditioning and during conditioning. Mean intake 


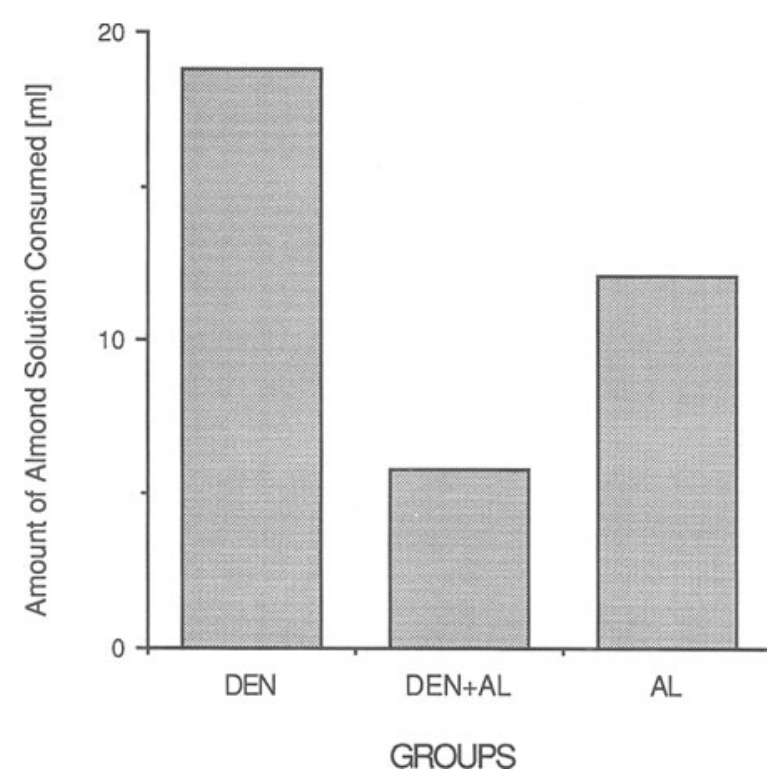

Figure 1. The mean almond-solution consumption in milliliters of Groups DEN, DEN + AL, and AL, Experiment 1a.

ranged from 16.9 to $17.2 \mathrm{ml}$ the day before conditioning and from 7.5 to $8.1 \mathrm{ml}$ during conditioning.

Figure 2 presents the mean denatonium intake for each group of Experiment $1 \mathrm{~b}$ over the 2 test days. A one-way ANOVA performed on Test Day 1 intake revealed a significant difference $[F(2,23)=8.92, p<.01]$. Betweengroup comparisons showed that the intake of the AL group was significantly greater than that in either the DEN or DEN + AL group. No other significant differences were observed.
The results of Experiments $1 \mathrm{a}$ and $1 \mathrm{~b}$ are unequivocal. When almond and denatonium are mixed together in compound, lithium-mediated aversion to the almond solution is potentiated whereas that to the denatonium solution is overshadowed. Almond aversion was significantly greater following compound conditioning than it was following single-element conditioning. In contrast, Experiment $1 \mathrm{~b}$ demonstrated that aversion to denatonium was significantly weaker in animals conditioned to its taste in compound with almond (DEN $+\mathrm{AL})$ than in those conditioned to denatonium by itself (DEN).

\section{EXPERIMENT 2}

\begin{abstract}
Method
Subjects, Apparatus, and Procedure (Experiment 2a). Subjects were 30 naive, adult male Holtzman rats. Animals were maintained under conditions similar to those previously described. The animals were matched into three groups (DEN-LI, $\mathrm{H}_{2} \mathrm{O} / \mathrm{LI}$, and $\mathrm{H}_{2} \mathrm{O} ; n=10$ ) on the basis of daily water intake for the last 8 days of fluid exposure. Conditioning occurred on the next day. On this occasion, each animal was given 10-min access to $10 \mathrm{ml}$ of the designated solution. Group DEN-LI received denatonium, and Groups $\mathrm{H}_{2} \mathrm{O} / \mathrm{LI}$ and $\mathrm{H}_{2} \mathrm{O}$ drank water. Fifteen minutes later, Group DEN-LI received an i.p. $\mathrm{LiCl}$ injection. The members of Group $\mathrm{H}_{2} \mathrm{O} / \mathrm{LI}$ received a noncontingent $\mathrm{LiCl}$ injection $2 \mathrm{~h}$ after fluid presentation, and Group $\mathrm{H}_{2} \mathrm{O}$ never received an $\mathrm{LiCl}$ injection. Five hours after conditioning, all animals received their daily water maintenance. Testing occurred $72 \mathrm{~h}$ after conditioning, with all animals receiving access to $30 \mathrm{ml}$ of the almond solution for $20 \mathrm{~min}$. The animals were tested over 2 consecutive days.

Subjects, Apparatus, and Procedure (Experiment 2b). Subjects in Experiment $2 b$ were 30 naive adult male Holtzman rats. They were divided into groups $(n=10)$ after receiving preexperimental treatments identical to those described for Experiment $2 \mathrm{a}$. The procedures and groups (Groups AL-LI, $\mathrm{H}_{2} \mathrm{O} / \mathrm{LI}$, and $\mathrm{H}_{2} \mathrm{O}$ ) for Experiment $2 \mathrm{~b}$ were identical to those of Experiment 2a except that the role of the conditioning and testing solutions was reversed (i.e., in the critical group of Experiment $2 \mathrm{~b}$, the almond solution was the conditioning solution and the denatonium saccharide was the test solution).
\end{abstract}

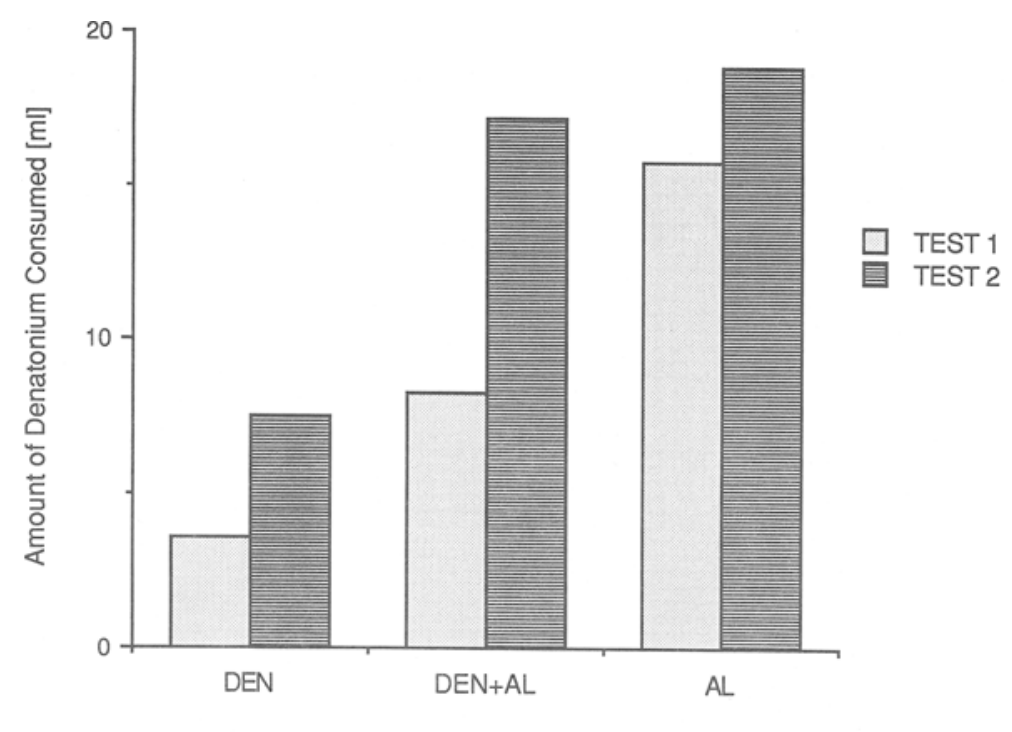

GROUPS

Figure 2. The mean denatonium-solution consumption in milliliters of Groups DEN, DEN + AL, and AL on Test Days 1 and 2, Experiment $1 b$. 


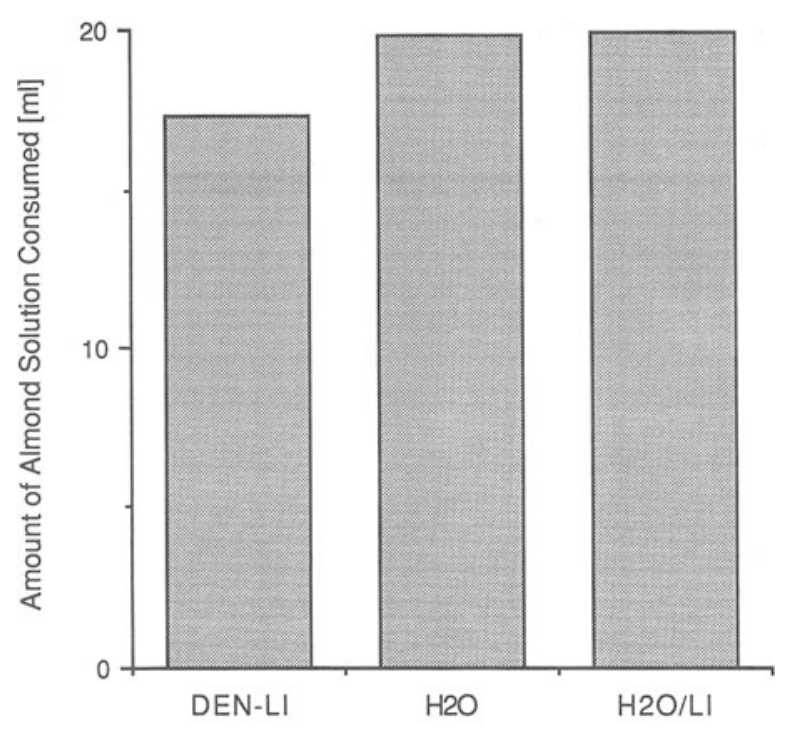

GROUPS

Figure 3. The mean almond-solution consumption in milliliters of Groups DEN-LI, $\mathrm{H}_{2} \mathrm{O}$, and $\mathrm{H}_{2} \mathrm{O} / \mathrm{LI}$, Experiment 2a.

\section{Results and Discussion}

Experiment 2a. The mean water intake of the groups prior to conditioning ranged from 22.0 to $22.1 \mathrm{ml}$. All groups drank relatively the same amount on the conditioning trial $(8.72$ to $9.15 \mathrm{ml})$.

Figure 3 presents the mean intake of almond solution on Test Day 1 for each of the three groups of Experiment 2a. Group DEN-LI drank less almond odor solution $(M=17.3 \mathrm{ml})$ than did Group $\mathrm{H}_{2} \mathrm{O} / \mathrm{LI}(M=19.9 \mathrm{ml})$

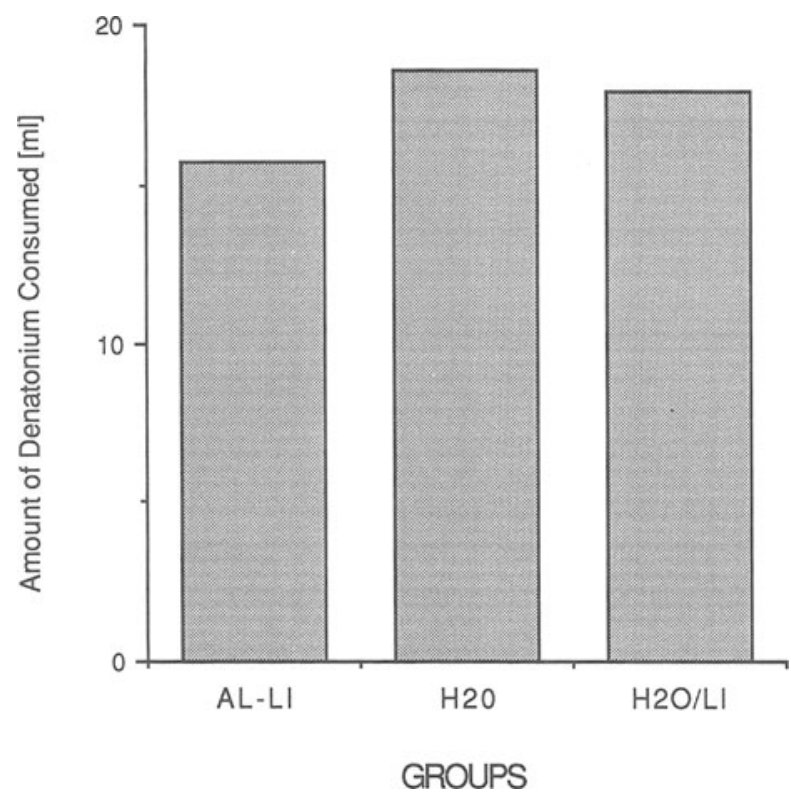

Figure 4. The mean denatonium-solution consumption in milliliters of Groups AL-LI, $\mathrm{H}_{2} \mathrm{O}$, and $\mathrm{H}_{2} \mathrm{O} / \mathrm{LI}$, Experiment $2 \mathrm{~b}$. or Group $\mathrm{H}_{2} \mathrm{O}(M=19.86 \mathrm{ml})$. However, this difference was not significant $[F(2,27)=1.96, p=.16]$. In addition, planned comparisons failed to reveal any betweengroup differences. Significant group differences were also not detected on Test Day $2[F(2,27)<1]$.

Experiment 2b. All groups drank equal amounts of water prior to conditioning $(M=23.5 \mathrm{ml})$. Conditioningday intake was also relatively similar $(8.4$ to $9 \mathrm{ml})$.

Figure 4 presents the mean consumption of denatonium by each group on Test Day 1 . Group means were: Group AL-LI $=15.72 \mathrm{ml}$; Group $\mathrm{H}_{2} \mathrm{O} / \mathrm{LI}=17.94 \mathrm{ml}$; and Group $\mathrm{H}_{2} \mathrm{O}=18.55 \mathrm{ml}$. A one-way ANOVA showed no significant differences $[F(2,27)=1.1, p=.36]$. Planned comparisons did not reveal any significant group differences. The results of Test Day 2 were similar $[F(2,27)<1]$.

Neither Experiment 2a nor Experiment $2 b$ revealed significant generalization from denatonium to almond or from almond to denatonium, respectively.

\section{GENERAL DISCUSSION}

Conditioning a denatonium-almond mixture produced enhanced aversion or potentiation to the almond element (Experiment 1a) and diminished or overshadowed aversion to the denatonium element (Experiment $1 \mathrm{~b}$ ). A simple interpretation of these outcomes is that denatonium aversion generalizes to almond, thereby producing potentiated aversion to the almond, but that almond aversion does not similarly generalize to denatonium, thereby resulting in overshadowing of denatonium. If this analysis is true, conditioning of denatonium alone should produce generalized aversion to almond and conditioning of almond alone should not result in generalized aversion to denatonium. Contrary to this prediction, aversion to either the almond or denatonium elements by themselves produced only small and statistically unreliable generalized aversion to the other fluid (Experiments $2 \mathrm{a}$ and $2 \mathrm{~b}$ ). These results indicate that stimulus generalization is not of central importance to the production of taste-mediated odor potentiation when the taste and odor elements are conditioned in a mixture. The minimal role played by generalized aversion in other types of taste-mediated potentiation is yet another common feature of most instances of potentiation. Such similarities suggest common underlying mechanisms in the various types of tastemediated potentiation currently documented in the literature (for a review, see LoLordo \& Droungas, 1989).

\section{REFERENCES}

Best, M. R., Brown, E. R., \& Sowell, M. L. (1984). Taste-mediated potentiation of noningestional stimuli in rats. Learning \& Motivation, 15, 244-258.

Bouton, M. E., Jones, D. L., McPhillips, S. A., SwartzenTRUBER, D. (1986). Potentiation and overshadowing in odor-aversion learning: Role of method of odor presentation, the distal-proximal cue distinction, and the conditionability of odor. Learning \& Motivation, 17, 115-138.

Durlach, P. J., \& Rescorla, R. A. (1980). Potentiation rather than overshadowing in flavor-aversion learning: An analysis in terms of within-compound associations. Journal of Experimental Psychology: Animal Behavior Processes, 6, 175-187.

Ellins, S. R., Cramer, R. E., \& Whitmore, C. (1985). Taste potentiation of auditory aversions in rats (Rattus norvegicus): A case for spatial contiguity. Journal of Comparative Psychology, 99, 108-111.

LoLordo, V. M., \& Droungas, A. (1989). Selective associations and adaptive specializations: Taste aversions and phobias. In S. B. Klein \& R. R. Mowrer (Eds.), Contemporary learning theories: Instrumental conditioning theory and the impact of biological constraints on learning (pp. 145-180). Hillsdale, NJ: Erlbaum.

(Manuscript received January 25, 1992.) 